\title{
Variability and Trends of Precipitation in Quelimane, Central Mozambique, and Their Relation to El Niño Southern Oscillation
}

\author{
Helder A. Machaieie ${ }^{1}$, Cleverson G. Silva ${ }^{2}$, Eduardo N. de Oliveira ${ }^{3}$, \\ Hilário I. T. Júnior ${ }^{1}$, Hermes A. de Almeida4 \\ ${ }^{1}$ School of Marine and Coastal Sciences, Eduardo Mondlane University, Quelimane, Mozambique \\ ${ }^{2}$ Department of Geology, Fluminense Federal University, Niterói, Brazil \\ ${ }^{3}$ Department of Physical Oceanography, Rio de Janeiro State University, Rio de Janeiro, Brazil \\ ${ }^{4}$ Department of Geography, Paraiba State University, Campina Grande, Brazil \\ Email: *machaielder@yahoo.com.br
}

How to cite this paper: Machaieie, $\mathrm{H}$. A., Silva, C. G., de Oliveira, E. N., Júnior, H. I. T. \& de Almeida, H. A. (2020). Variability and Trends of Precipitation in Quelimane, Central Mozambique, and Their Relation to El Niño Southern Oscillation. Journal of Geoscience and Environment Protection, 8, $1-16$.

https://doi.org/10.4236/gep.2020.87001

Received: March 5, 2020

Accepted: July 11, 2020

Published: July 14, 2020

Copyright $\odot 2020$ by author(s) and Scientific Research Publishing Inc. This work is licensed under the Creative Commons Attribution International License (CC BY 4.0).

http://creativecommons.org/licenses/by/4.0/

\section{(c) (i) Open Access}

\begin{abstract}
Understanding precipitation variability and trends is very important for sustainable water management. In this paper, we used 65 years (1951-2016) longterm precipitation data to evaluate the precipitation variability and trends in Quelimane, and their relation to El Niño Southern Oscillation (ENSO). The analysis includes annual, inter-annual inter-decadal variations, Mann-Kendall trend test, and drought frequency. The study also evaluated the relationship between Oceanic Niño Index (ONI) and precipitation patterns during ENSO positive, normal and negative phases. The results show two distinct seasons of precipitation in Quelimane, the wet season extending between December and April and the dry season extending from May to November. ENSO was found to influence the inter-annual variations of precipitation during the wet season, with warm ENSO (El Niño) and cold (La Niña) events tending to reduce and increase the precipitation amounts, respectively. Decreasing trends in inter-annual variations of precipitation and increase of drought frequency and severity are highlighted in this study. Both decreasing trend of inter-annual variations and increasing of drought frequency and severity have intensified after the 1970s climate shift. These intensifications seem to be associated with the strengthening of ENSO after the 1970s climate shift. The results of the present study may be useful for the design of the climate change adaptation plans in central Mozambique.
\end{abstract}

\section{Keywords}

Climate Shift, Variability and Trends, Precipitation, ENSO, Quelimane 


\section{Introduction}

Water is a key resource for the economic development and food production, considering the fact that both agriculture and industry sectors are heavily dependent on water availability. During the last century, the surface temperature has increased by almost $1^{\circ} \mathrm{C}$ on average, although this value might have been higher in some regions and lower in others. In parallel to temperature increasing, there has been significant reduction in water levels of rivers and lakes, and in precipitation quantity and periodicity due to natural and anthropogenic factors including El Niño Southern Oscillation (ENSO) and changes in the atmospheric circulation (Alley et al., 2007).

Overall, long-term observations of precipitation have shown pronounced trends in the last hundred years, where some places became wetter while others such as Sahel, Mediterranean, and Southern Africa are drying gradually. In general, long-term observations highlight strong inter-annual variations with long periods of droughts interspersed by a year of heavy rain, in response to ENSO (Alley et al., 2007). However, studies conducted in different geographical locations have shown that the effects of ENSO in precipitation can vary from place to place; therefore, the analysis of ENSO-precipitation relation on local scale is important.

The consequences of extreme weather such as floods and droughts have devastating effects in Southern Africa due to poor infrastructure and sanitation observed in most regions (Fauchereu et al., 2003). Although there is still limited research about the mechanisms, previous studies found that ENSO tends to decrease the precipitation in Southern Africa mostly during Austral summer season (December to March) when ENSO has reached maturity (Mason \& Jury, 1997; Ratnam et al., 2014). The mid-1970s have been designated as the last change point of global climate regime due to abrupt changes in environmental conditions in the Pacific Basin (Meehl et al., 2009). Previous studies, including the researches by Richard et al., (2000), Mason (2001) and Marengo (2008) have pointed out that precipitation pattern has changed after the 1970's decade, also known as the 1970's climate shift. Studies from Gaughan \& Waylen (2012), Gaughan et al. (2016) and Nicholson et al. (2018) found out that after 1970s the drought frequency has increased in some sub-regions of Southern Africa, including the Lower Zambezi basin.

Quelimane is located in central Mozambique and most of its population has precipitation-fed rice farming as their main source of income, and therefore, the droughts have dramatic social economic impacts. Although there are some studies addressed to the variability of precipitation of Southern Africa and its relationship to ENSO, there are imited published studies based on local data for central Mozambique, for instance. It should be mentioned, however, that such studies are more valuable since they add to the studies conducted at a regional scale, which are based on station aggregation and coarse space network average. In view of the above, this study aimed at evaluating the temporal variability and 
trends of precipitation in Quelimane, and their relation to ENSO, focusing on the periods pre and post-1970s climate shift. The results of the present study can be applied in the design of the climate change adaptation plans in central Mozambique.

\section{Material and Methods}

\subsection{Study Area}

Quelimane (Figure 1) is the capital of Zambézia province, which is located in central Mozambique at the latitude of $17.87^{\circ} \mathrm{S}$ and Longitude $36.94^{\circ} \mathrm{E}$. According to INAE (2011) the air temperature in Quelimane ranges between $10.3^{\circ} \mathrm{C}$ and $42.5^{\circ} \mathrm{C}$, the monthly mean precipitation is about $72 \mathrm{~mm}$, and mean relative humidity is $74.9 \%$. According to Kottek et al. (2006), the climate of Quelimane is equatorial savannah with dry winter.

\subsection{Data Source}

Monthly data of precipitation for the years between 1951 and 2016 were obtained from archives of National Institute of Meteorology for Mozambique at the Quelimane Meteorological Station. In addition, the mean monthly data of Oceanic Niño Index (ONI) for the period 1951-2016 was obtained from database of Golden Gate Weather Services (GGWS). The ONI is used for identifying the occurrence of El Niño (warm) and La Niña (cold) events in the Tropical Pacific. The ONI was based on 3-month running mean of Sea Surface Temperature anomaly in the Niño 3.4 region $\left(5^{\circ} \mathrm{N}-5^{\circ} \mathrm{S}, 120^{\circ} \mathrm{W}-170^{\circ} \mathrm{W}\right)$. El Niño event is considered when the ONI exceeds the $+0.5^{\circ}$ threshold values for a period of at least 5 consecutive months. Conversely, La Niña events are defined as periods

\section{Geographical Location of Quelimane City}

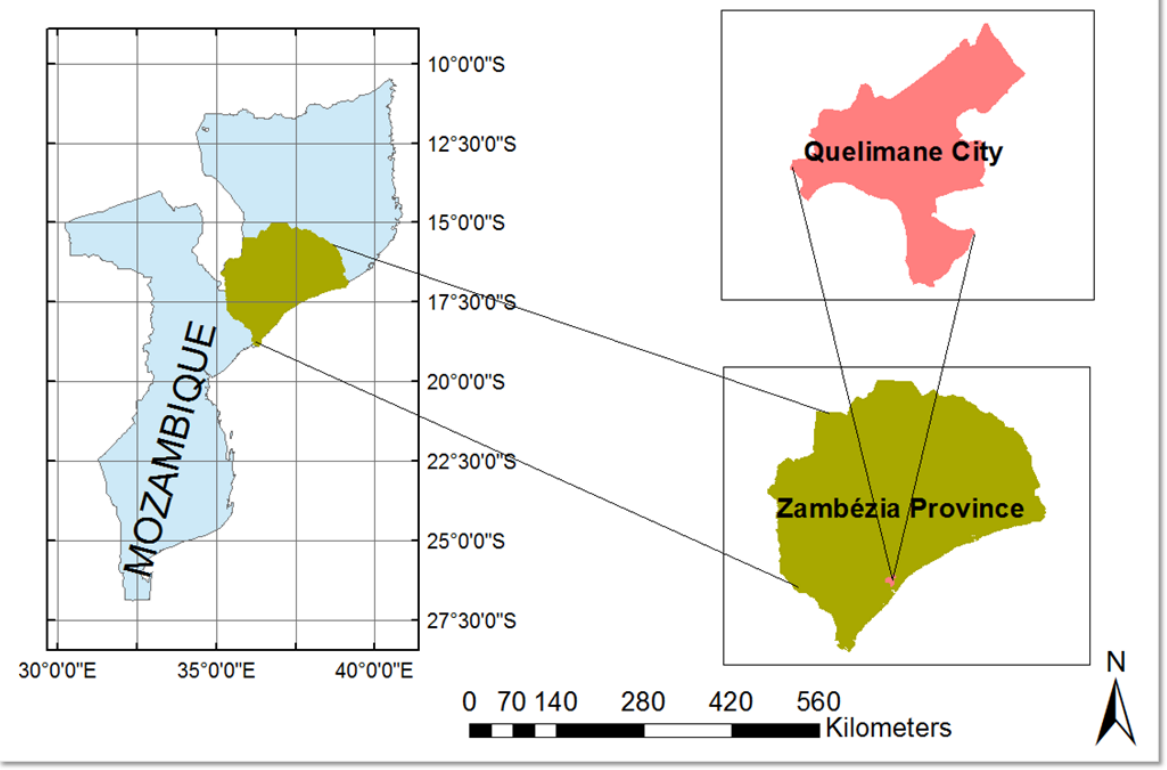

Figure 1. Geographical location of Quelimane. 
with at least five consecutive months with ONI below -0.5 . Periods with ONI below +0.5 and above -0.5 are classified as normal periods.

\subsection{Data Analysis}

In general, this study focuses on three main analysis, namely variability, trend detection and relationship between precipitation in Quelimane and ENSO. The analysis of variability was performed using monthly climatology data, and standardized precipitation anomaly, which allowed inferring the annual cycle, drought frequency and severity before and after the 1970s climate shift. The standardized precipitation anomaly was calculated as follows (Angnew \& Chappel, 1999).

$$
P_{a}=\frac{P_{t}-P_{m}}{\sigma}
$$

Precipitation anomaly, $P_{t}$ is the total annual precipitation in year $t, P_{m}$ is the mean precipitation over a specific period. For comparison of frequency and severity between years (1951-1975) and (1980-2016), it was used the dataset from 1951-2016 period to determine the mean precipitation for both periods. $\sigma$ is the standard deviation of precipitation for 1951-2016 period. The droughts were categorized into extreme drought $\left(P_{a}<-1.65\right)$, severe $\left(-1.28>P_{a}>-1.65\right)$, moderate drought $\left(-0.84>P_{a}>-1.28\right)$ and no drought $\left(P_{a}>-0.84\right)$, folowing the criteria used by Angnew \& Chappel, (1999). To normalize the difference in sample size between period 1 (prior climate shift, 25 years) and period 2 (after climate shift, 37 years), the drought frequency was estimated as the number of droughts per decade, given by the following equation:

$$
\text { Freq }=\frac{10 * n}{\lambda}
$$

where: Freq. is the drought frequency, $n$ is the number of drought in years for the period, and $\lambda$ is the sample size.

Trend detection and analysis were determined using Mann-Kendall nonparametric test and Sen's estimator of slope. The goal of Mann-Kendall (MK) nonparametric test (Mann, 1945; Kendall, 1975) is to infer if there is a monotonic upward or downward trend in a time series. The Mann-Kendall parameter is widely used to evaluate the trends of hydrological and meteorological time series. In this study, the Mann-Kendall test was applied to detect the trend of annual, seasonal and monthly precipitation in Quelimane. The MK test is a two-tailed test. It tests to reject the null hypothesis $\left(h_{0}\right)$, which is "the absence of trend" and accept the alternative hypothesis $\left(h_{1}\right)$, which is "existence of a monotonic trend in the time series". The MK statistic $S$ in a time of series of $n$ elements is given in Equation (3).

$$
S=\sum_{k=1}^{n-1} \sum \frac{n}{j=k+1} \operatorname{sgn}\left(x_{j}-x_{k}\right)
$$

where $n$ is the number of data point, $x_{j}$ and $x_{k}$ are the annual values in years $j$ 
and $k, j>k$, respectively. The Sign function is computed as follows:

$$
\begin{array}{rlll}
+1 & \text { if } & x_{j}-x_{k}>0 \\
\operatorname{Sgn}\left(x_{j}=x_{k}\right)=0 & \text { if } & x_{j}-x_{k}=0 \\
-1 & \text { if } & x_{j}-x_{k}<0
\end{array}
$$

When the number of observation is more than 10 , the statistic $S$ is assumed to be approximately normally distributed, with mean $E(S)=0$ (Kendall, 1975). In this case, the variance $\operatorname{Var}(S)$ can be obtained through Equation (5) where $t_{i}$ is the number of ties of length $i$.

$$
\operatorname{Var}(S)=\frac{1}{18}\left[n(n-1)(2 n+5)-\sum_{i=1}^{n} t_{i}(i-1)(2 i+5) i\right]
$$

The dimensionless statistic test $Z$ (Equation (6)) follows a normal distribution, where positive (negative) values indicate upwards (downwards) trend, and is given by:

$$
Z=\left\{\begin{array}{cc}
\frac{S-1}{\sqrt{\operatorname{Var}(S)}} & \text { if } S>0 \\
0 & \text { if } S=0 \\
\frac{S+1}{\sqrt{\operatorname{Var}(S)}} & \text { if } S<0
\end{array}\right.
$$

In the case of two-sided test the $h_{0}$ is rejected and $h_{1}$ is accepted if $[Z]$ is higher that $Z_{\alpha / 2}$.

In this study the hypothesis was tested at 95\% confidence level, where $\alpha=$ 0.05. The slope of precipitation trend was computed using Sen's estimator (Sen, 1968). According to this method the slope $T_{i}$ of any two values of time series $\mathrm{x}$ can be estimated through the following equation:

$$
T_{i}=\frac{x_{j}-x_{i}}{j-1}
$$

where $x_{i}$ and $x_{j}$ are data values at time $j$ and $i(j>i)$ correspondingly. The median of these $N$ values of $T_{i}$ is represented as Sen's estimator of slope and is determined as $Q=T(N+1) / 2$ if $N$ is odd and $Q=\left[T_{(N / 2)+} T\left(_{(N+2) / 2}\right) / 2\right]$ if $N$ is even. Positive value of $Q$ indicates an upwards trend and negative value of $Q$ indicates a downwards trend.

To evaluate the relationship between ENSO and precipitation, 3-month moving average time series of precipitation was computed from mean monthly data, in order to match the 3-month moving average of ONI. For each trimester, correlation analysis between ONI and precipitation and comparisons of precipitation climatology for Positive, Normal, and Negative ONI were performed. The ONI is defined as Positive if ONI $\geq 0.5$, Normal if $-0.5<\mathrm{ONI}<0.5$, and Negative if ONI $\leq-0.5$ (Figure 2). Additionally, percentage of the anomalies of accumulative annual precipitation was calculated to point out how the precipitation in a specific ENSO year deviates from the historical means (Equation (8)).

$$
A n=\frac{P A^{*} 100}{P M}-100
$$


where $A n$ denotes the percentage of the anomaly of precipitation for a given year; $P A$ denotes the annual accumulated precipitation; $P M$ denotes the historical mean of the annual accumulated precipitation.

\section{Results}

Variation in annual precipitation shows similar patterns in the three periods; 1951-1971, 1951-2016 and 1980-2016 (Figure 3). Wet season extends from December to April with mean monthly precipitation of $140 \mathrm{~mm} / \mathrm{month}$ in April and $275 \mathrm{~mm} /$ month in January. The dry season is between May and November with the mean monthly precipitation of $15 \mathrm{~mm} /$ month in September and 100 $\mathrm{mm}$ /month in November. Comparing the monthly climatology for the periods 1951-1975 and 1980-2016 it was noted that after the climate shift, the precipitation amounts decreased in most of the months, having increased only in January, July and October.

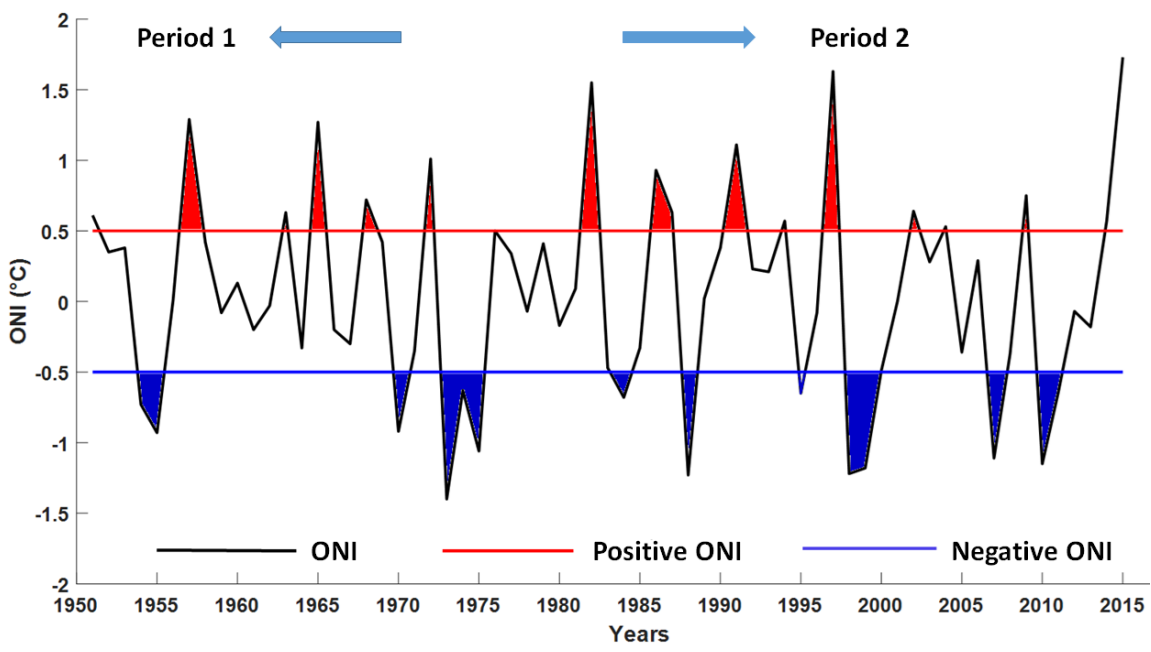

Figure 2. Variation of ONI during 1951-2016. The rectangle marks the shift period. Red and blue represent the threshold value of positive and negative ONI, respectively. Period 1 and period 2 correspond to the periods pre and post 1970s climate shift.

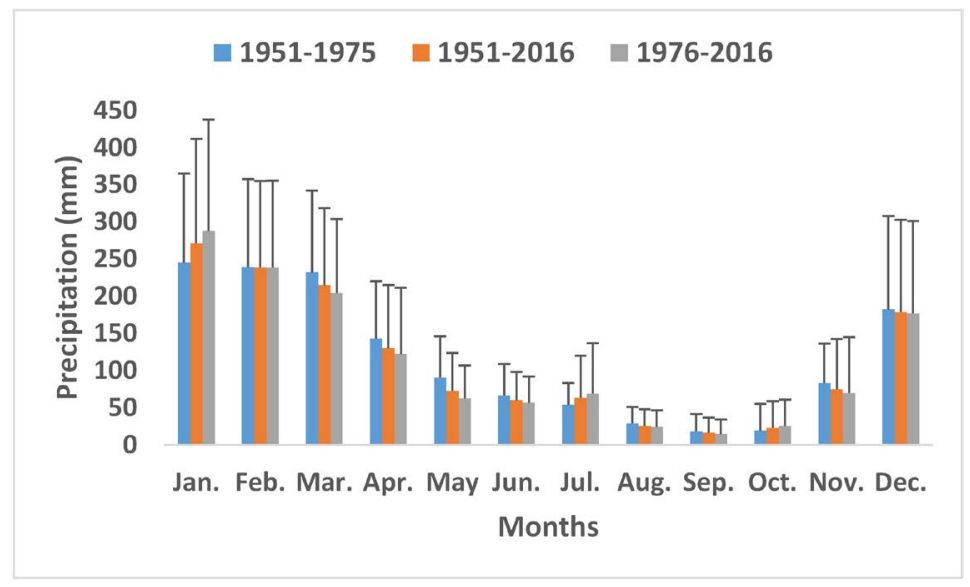

Figure 3. Climatology of annual variation of precipitation in Quelimane. 
Figure 4 shows drought frequency and severity in Quelimane for total annual precipitation (January-December), wet Season (December-April) and dry season (May-November) and for the three selected periods (1951-1975, 1951-2016 and 1980-2016). Comparing the droughts of the periods 1951-1975 and 1980-2016, the number of droughts per decade increased from 2.0 to 3.0 for total annual precipitation, from 0.5 to 3.0 for the dry season while wet season remained at about 2.0 droughts per decade. The pattern of moderated drought during 19511975 and 1980-2016 periods showed a rise for total annual precipitation and dry season and there was a decrease during wet season. The registered increase was from 1.2 to 1.5 for total annual precipitation, 0.4 to 1.4 for dry season and the decrease was from 2.0 to 0.5 in wet season. Severe droughts during 1980-2016 showed raise for all seasons when compared to 1951-1975, having increased from 0.8 to 1.6 for total annual precipitation, from 0.0 to 1.4 for the wet season,
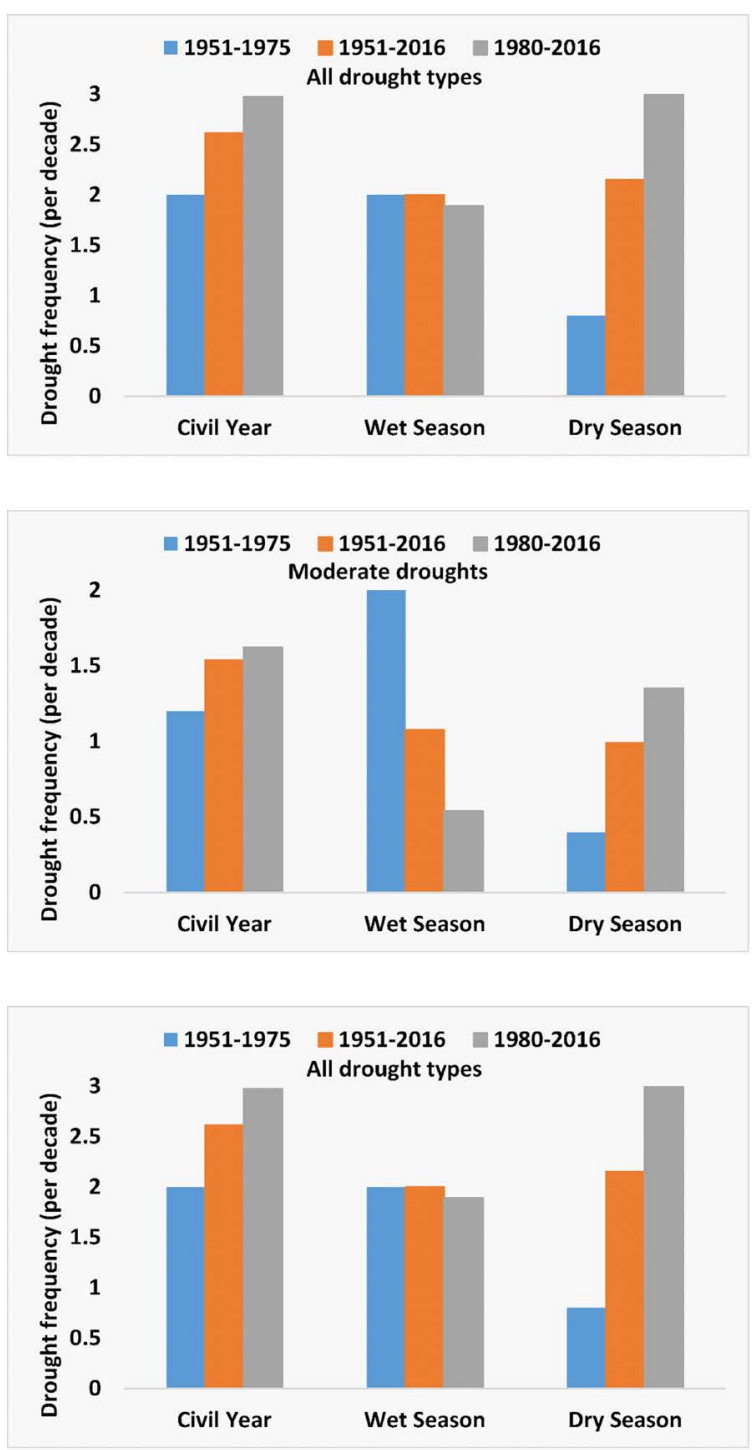

Figure 4. Frequency of different drought categories (in number of droughts per decade) for the periods 1951-1975, 1951-2016 and 1980-2016. 
and from 0.3 to 1.4 droughts per decade for the dry season.

Inter-annual variation (Figure 5) showed considerable oscillations among the different years of the time series and negative trend for all the time series. For
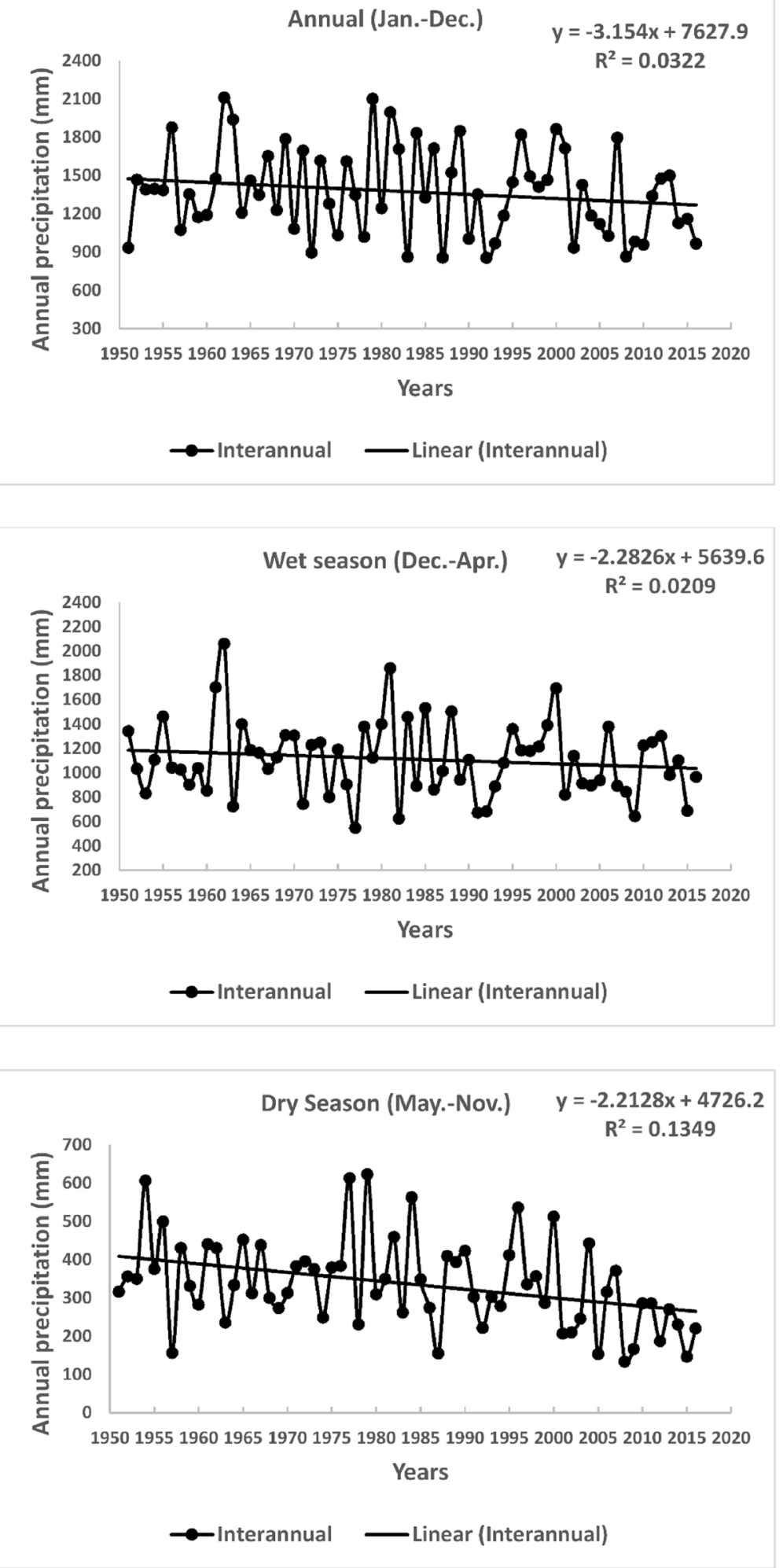

Figure 5. Precipitation pattern (total annual, wet and dry seasons) during 1951-2016. 
total annual precipitation, which had similar pattern to wet season, the total annual precipitation varied between about $900 \mathrm{~mm}$ in years 1951, 1871, 1984, 1987, 1992, 2002 and 2008 and $2100 \mathrm{~mm}$ in years 1962, 1979 and 1981. There were three noticeable time intervals in the time series, namely, 1961-1977, 1977-1990 and 2008-2016. During 1965-1977, the total annual precipitation presents smaller peaks and smaller amplitudes between wetter and drier years. The time interval 1977-1990 is characterized by higher amplitude between wetter and drier years. From 1977 to 1978, for example, there was an increase of about $133 \%$ in the total annual precipitation. In the $2008-2016$, there were fewer peaks such that in most of the years the precipitation amounts were lower than historical mean. For dry season, it is possible to highlight five driest years of the time series (1957, 1987, 2005, 2008 and 2016) and four sub-periods, 1957-1976, 1977-1984, 1995-2007 and 2008-2016. The 1957-1976 interval was relatively drier than 1977-1984 and 1995-2007, presents smaller peaks and relatively lower variation between lower and higher precipitation amounts. The 1977-1984 and 1995-2007 periods are wetter and present higher peaks and relatively higher variations between peaks and droughts. Likewise to total annual precipitation and wet season the 2008-2016 period of the dry season presents fewer peaks and precipitation amounts below the mean value of the time series.

Mann-Kendall test and Sen's estimator of slope for monthly, wet season (Dec.-Apr.), dry season (May-Nov.) and annual (Jan.-Dec.) during the periods 1951-1975, 1951-2016 and 1980-2016 are presented in Figure 6 and Figure 7. In agreement with the trend line presented in Figure 5, the result of Mann-Kendall test ( $Z$-value, Figure 6) also shows downward trends for most of the time series, except for January and October of years 1951-2016, March, April, July and October and wet season of the period 1951-1975, and January of the period 1980-2016.

The maximum increasing trend's slope, as given by the Sen's estimator ( $Q$-value, Figure 7) was about $4 \mathrm{~mm}$, observed in April of 1951-1975 period while the highest decreasing trend's slopes were $8 \mathrm{~mm}$, observed during the period 1980-2016. Comparing the values of trend's slope for the periods before (1951-1975) and

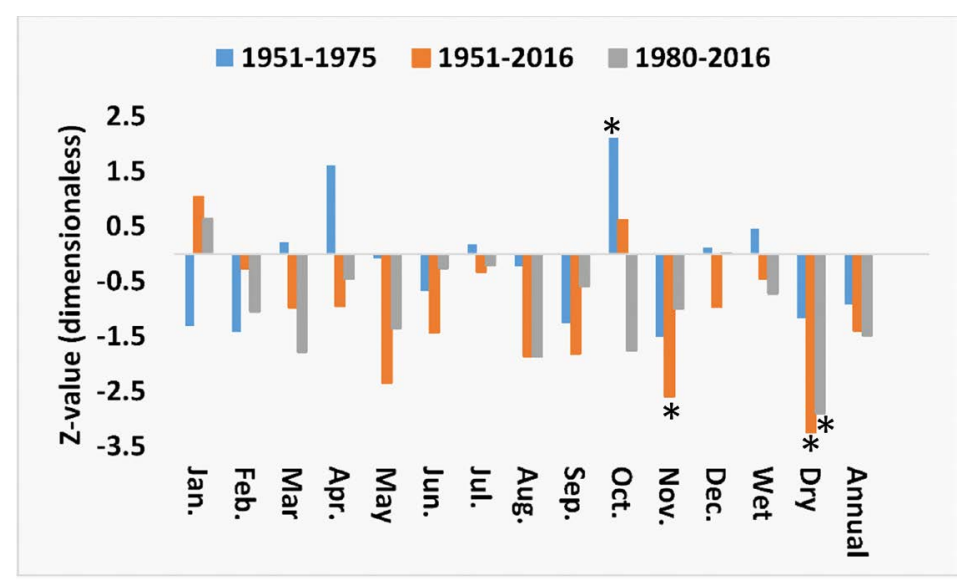

Figure 6. Mann-Kendall trend test of precipitation in Quelimane. ${ }^{*}$ indicates statistically significant trend at $95 \%$ confidence level. 


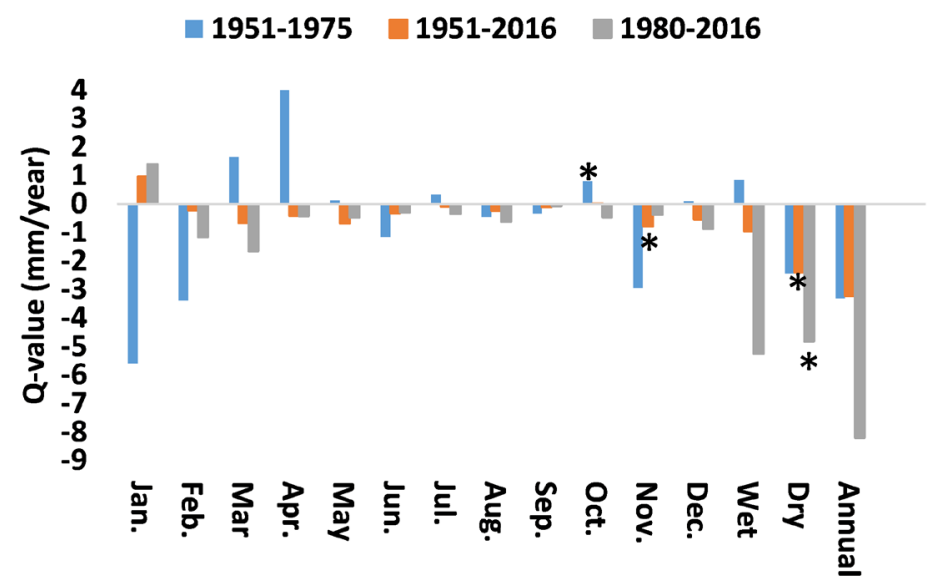

Figure 7. Sen's slope of precipitation in Quelimane. * indicates statistically significant trend at $95 \%$ confidence level.

after climate shift (1980-2016) it is possible to note that in ten of the fifteen data series the slope value became more negative during period 1980-2016, denoting intensifications of negative trends of precipitation. The highest intensifications of negative trends in the period 1980-2016 were observed in the annual data set, wet and dry seasons where the slope values varied from -4 to -8 , from 1 to -5.5 and from -2 to $-5 \mathrm{~mm} /$ year, respectively. The highest attenuations of negative trend was observed in January, February and November where the slope values increased from -5.5 to +1.5 , from -4 to +1 and from -3 to -0.5 , respectively. However, the only statistically significant trends, at $95 \%$ of confidence level, were from October and November of 1951-1975 period and dry season of 1951-2016 and 1980-2016.

Figure 8 shows the correlation coefficient between ONI and trimestral averages of precipitation, for the periods 1951-1875, 1951-2016 and 1980-2016. The correlation coefficient values varied between -0.5 in February-March-April (FMA) and March-April-May (MAM) of 1980-2016 period and 0.2 in August-September-October (ASO) of 1980-2016 and September-October-November (SON) of periods 1951-1975 and 1951-2016. Similarly to drought frequency and Sen's estimator of slope (Figure 4 and Figure 7), the correlation coefficient is stronger in period 1980-2016 than in period 1951-1975 in most of the trimesters with lower and non-statistically significant values during 1951-1975 period and relatively higher and statistically significant values during 1980-2016 period. The biggest strengths of the correlation coefficient in the period 1980-2016 in relation to the period 1951-1975 were observed in FMA, MAM, and April-May-June (AMJ) where the correlation coefficient varied from -0.15 to about -0.5 , from about -0.20 to about -0.5 and from about -0.15 to about -0.45 , respectively. The weakening of correlation coefficient during 1980-2016 period in relation to 1951-1975 period was observed only in July-August-September (JAS) and SON, where it varied from -0.4 to -0.18 and from 0.15 to 0.10 , respectively.

The trimestral means of precipitation for positive ONI, normal ONI and negative 


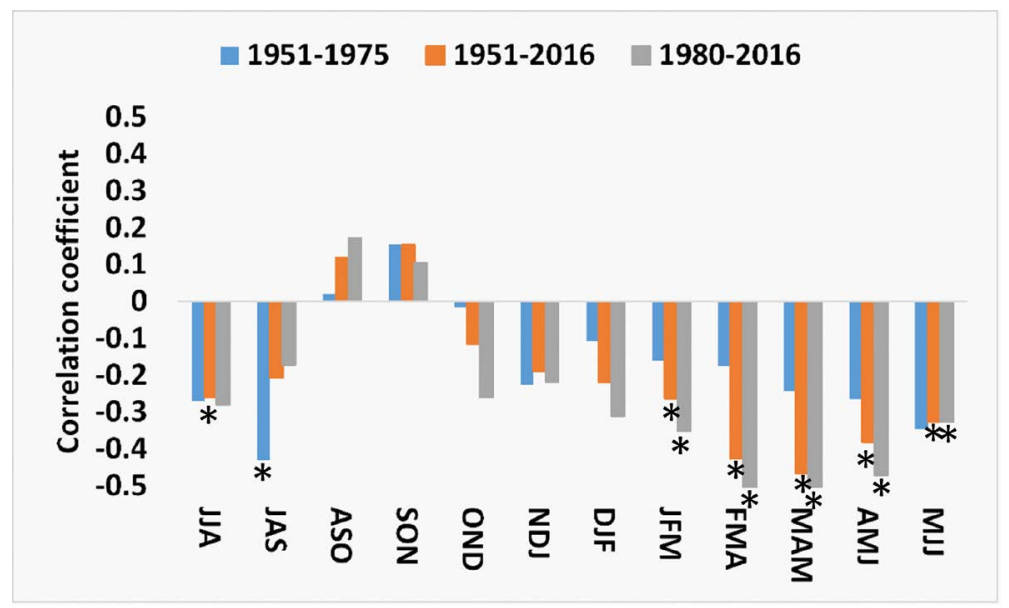

Figure 8. Correlation coefficient between ONI and precipitation. ${ }^{\star}$ indicates statistically significant values at $95 \%$ confidence level.

ONI (Figure 9) are plotted for the three selected periods, (1951-1975, 1951-2016 and 1980-2016) in order to infer possible changes in the ENSO-precipitation relationship after the 1970s climate shift. At first approach, one can see that there are no noticeable differences in the precipitation pattern of normal ONI for all three periods. On the other hand, there are noticeable differences in precipitation values of positive and negative ONI in periods 1951-1975 and 1980-2016. While the normal ONI precipitation tends to be similar in the three periods, the positive (negative) ONI precipitation values in the 1980-2016 period tend to be relatively low (high) compared to the 1951-1975 period in most of the trimesters. During November-December-January (NDJ), December-January-February (DJF), and January-February-March (JFM) of the 1951-1975 period, for example, the precipitation values of negative ONI were lower than those of normal ONI but in the 1980-2016 period, they increased in about $20 \mathrm{~mm}$ and became higher than those of normal ONI. On the contrary, during FMA, MAM, AMJ, May-June-July (MJJ), the positive ONI precipitation of 1980-2016 period shows relatively low values compared to 1951-1975 period.

Overall, it can be stated that while in the 1951-1975 period the ONI-precipitation relationship was less clear, in 1980-2016 period the amount of precipitation tended to be below (above) that of normal ONI when positive (negative) ONI events were observed. However, the inverse relationship between ONI and precipitation is not observed in some of dry season trimesters, namely ASO, and SON. It should be noted that the largest discrepancy in precipitation values of the three ONI classes are observed in wet season (FMA and MAM) where the value of precipitation amount during a positive ONI event can be $60 \mathrm{~mm}$ below that of normal ONI and during a negative ONI, it can reach $20 \mathrm{~mm}$ above that of normal ONI.

\section{Discussion}

Climatology of annual variation of precipitation in Quelimane (Figure 3) showed 

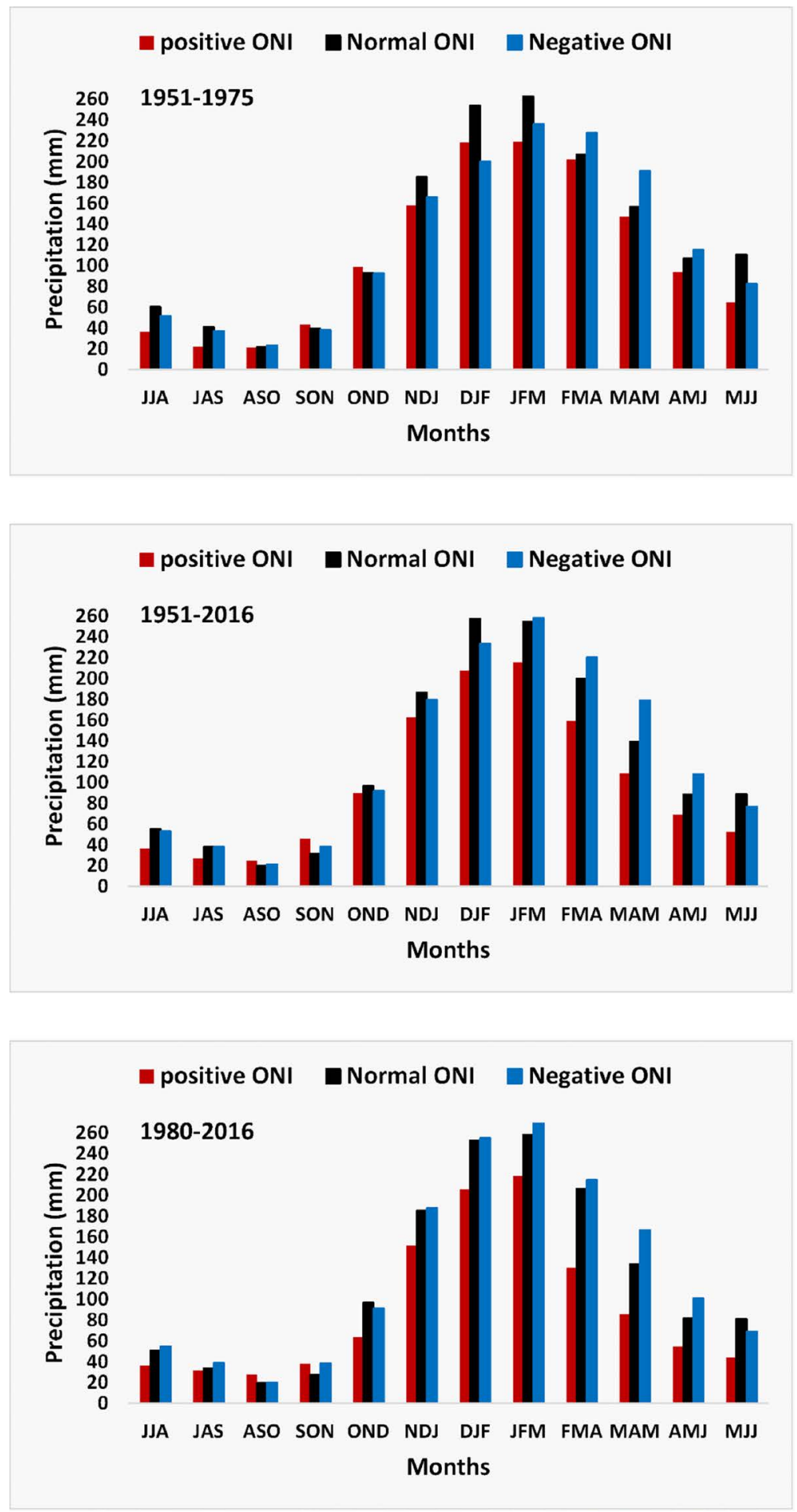

Figure 9. Trimestral precipitation mean during positive, normal and negative ONI, computed for the periods 1951-1975, 1951-2016, and 1980-2016.

that there were two distinct seasons of precipitation, the wet season extending from December to April and the dry season extending between May and November. The highest precipitation amounts were observed in summer, in response to the southern migration of the Inter-Tropical Convergence Zone dur- 
ing the austral summer months as reported Aimola \& Moura (2016). Overall, El Niño (La Niña) years tend to be associated to drier (wetter) conditions in response to a high (low) pressure center which dominates the southern Africa during warm (cold) phases of ENSO, repressing (enhancing) convection and rainfall (Nicholson \& Kim, 1997; Reason \& Jagadheesha, 2005). This pattern is also observed in the present study for Quelimane, where most of the drier years (e.g. 1957-1958, 1965-1966, 1982-1983, 1991-1992, 2015-2016) are associated to warm phases of ENSO while wetter years (e.g. 1955-1956, 1988-1989, 199-2000) are associated to cold phases of ENSO. However, the relationship between the ENSO and precipitation does not seem to be linear. An example of non-linearity is the difference in precipitation amounts during 1997-1998 strong El Niño and 1991-1992 and 2002-2003 moderate El Niño. The year 1997-1998 was expected to be drier than 1991-1992 and 2002-2003 due to the strong El Niño but it was relatively wetter for all the three seasons (total annual precipitation, wet and dry seasons), suggesting that the impact of El Niño in this year was not as strong as would be expected.

These findings corroborate with the study from Reason \& Jagadheesha (2005) who compared the NDJ and JFM precipitation anomalies in Southern Africa using NCEP reanalysis data. According to Reason \& Jagadheesha (2005) the source for the difference in ENSO impact was the strength of the Angola Low, which together with other local and regional forcings, including Atlantic and Indian Ocean also play a role on inter-annual variability of precipitation in Southern Africa (Nicholson \& Kim, 1997; Reason \& Jagadheesha, 2005). Moreover, the general pattern of drier conditions during El Niño and wetter conditions during La Niña is not evident in the composites of some dry season trimesters (ASO and SON, Figure 9), which may be an indication of overcoming of the impact of ENSO on inter-annual variation by the inter-decadal variation.

To assess the possible overcoming of ENSO impact by inter-decadal variation we plotted the inter-annual variation of SON precipitation anomalies (Figure 10). In inter-annual time scale one can note that the SON precipitation is randomly distributed in relation do ONI. On the other hand, it is possible to distinguish three sub-periods in decadal scale: 1951-1976, 1977-1989, and 19902015. The 1951-1976 sub-period, before the climate shift, presents intermediate conditions with a balance in the number of dry and wet years. The 1977-1989 sub-period, which includes the climate shift period and the beginning of the post-climate shift period, was a very wet sub-period such that it held the four wettest years (1977, 1979, 1982, 1984), two of which were El Niño years (1977, 1982). By contrast, between 1990 and 2015 after climate shift, more than $80 \%$ of years presented SON precipitation below the historical mean. The 1990-2015 sub-period also held five of the six driest SON precipitation years, four of which were normal years. This suggests that the impact of ENSO on inter-annual precipitation pattern is more discernible in the wet season, and is masked by the inter-decadal variations in some months of the dry season. 


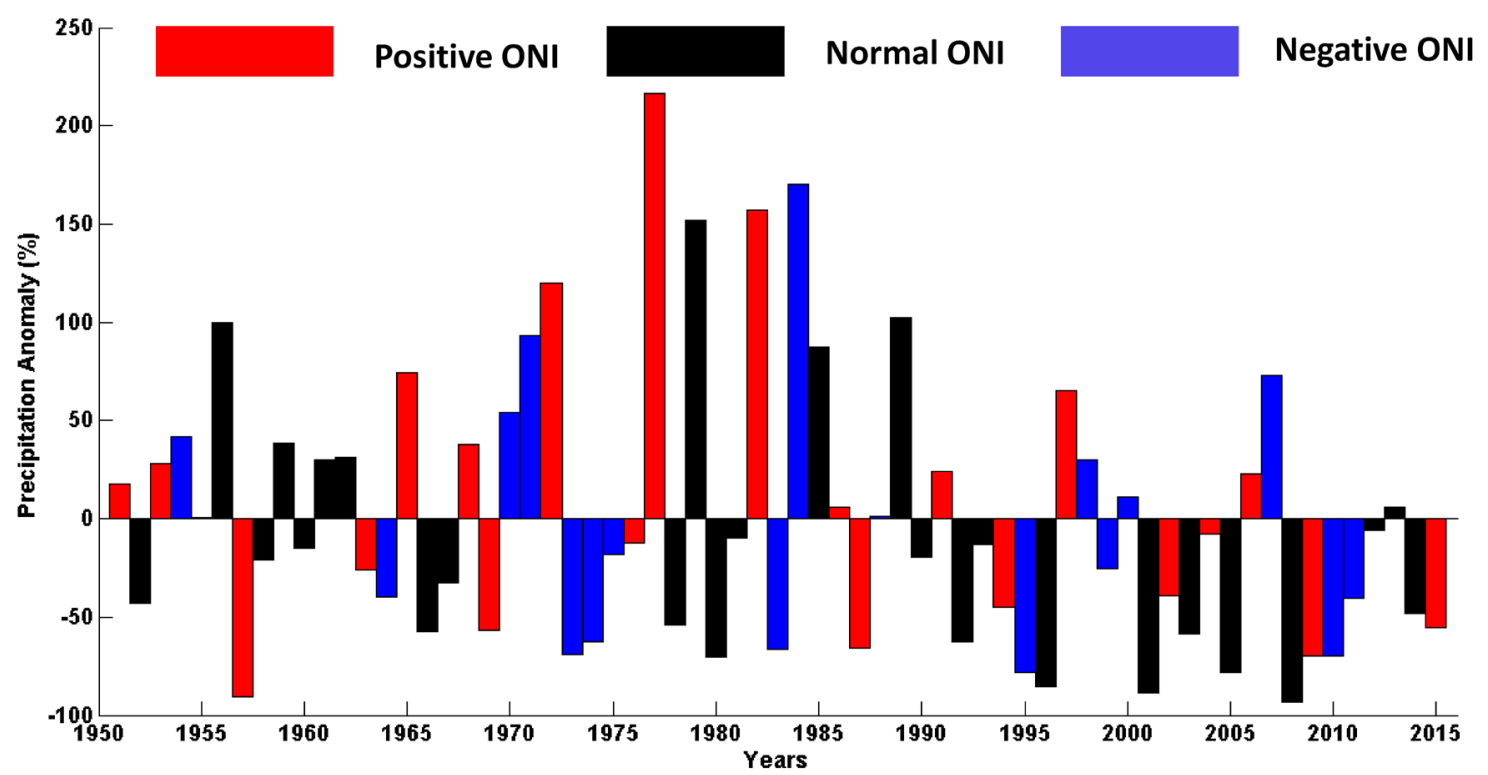

Figure 10. Inter-annual variation of SON precipitation anomalies in Quelimane and ENSO events.

In general, the comparisons of precipitation patterns during the periods before and after the 1970s climate shift (1951-1975, 1980-2016) showed a tendency of drier conditions as evidenced by reduction in monthly mean precipitation in all months except in January (Figure 3), increasing in frequency and severity of droughts, and negative Mann-Kendall and Sens's Slope (Figure 4, Figure 6, Figure 7). The drier conditions in later decades were in line with intensification of the negative correlation between ONI and precipitation (Figure 8), specially in wet season months, suggesting strengthening of ENSO impact. Previous studies by Richard et al. (2000), Rouault \& Richard (2005), and Monerie et al. (2019), also pointed out strengthening of the ENSO impact on Southern African precipitation in recent decades. With regards to the cause of the modification of the impact of ENSO on precipitation in recent years, the change in the climate state, associated to the increasing in Sea Surface temperature over the Equatorial Pacific Ocean under global warming (Wang et al., 2019), might be the main cause.

\section{Conclusion}

The precipitation in Quelimane presents two distinct seasons, the wet season extending between December and April and the dry season extending between May and November. The inter-annual time series revealed that the precipitation in Quelimane presents a significant year-to-year variation and pronounced inter-decadal oscillations. Mann-Kendall trend analysis of monthly, seasonal and annual time series revealed that overall, the precipitation in Quelimane is decreasing and the decreasing rate intensified after the 1970s climate shift. However only three of forty-five-time series presented statistically significant trends. The evaluation of the variation of drought frequency showed increase in both frequency and severity of droughts after the 1970s climate shift such that all of 
the severe droughts for the wet season occurred after the climate shift.

El Niño influence was found to be more discernible on wet season precipitation with warm ENSO events (El Niño) tending to reduce the precipitation and cold ENSO events (La Niña) tending to increase the precipitation amounts in Quelimane. For the dry season, the influence of ENSO is overcome by inter-decadal variation. Moreover, the intensification of the decreasing trend along with the increase of drought frequency and severity seems to be associated with the strengthening of ENSO impact after the 1970s climate shift.

The results of the present research suggest that the reduction in agricultural production due to precipitation scarcity may increase in the future. This study used long-term dataset of only one meteorological station due to a lack of continuous long-term data from other stations of Central Mozambique. Further research should be carried out on validating long-term data of satellite-estimated precipitation to evaluate the variability and trends of precipitation in the entire central Mozambique region.

\section{Acknowledgements}

The authors would like to thank Professor Antonio Hoguane and Mr. Everest Nduwa for their constructive comments and suggestions.

\section{Conflicts of Interest}

The authors declare no conflicts of interest regarding the publication of this paper.

\section{References}

Aimola, L., \& Moura, M. (2016). The Influence of Revolving Meridional Atantic Circulation in Defining the Average Position of the ITCZ in Northern Equator. Brazilian Journal of Meteorology, 31, 555-563. https://doi.org/10.1590/0102-7786312314b20150059

Alley, R., Berntsen, T., Bindoff, N. L., Chen, Z., Chidthaisong, A., Friedlingstein, P. et al. (2007). Climate Change 2007: The Physical Science Basis. Summary for Policymakers. Geneva: Intergovernamental Panel on Climate Change.

Angnew, C. T., \& Chappel, A. (1999). Drought in the Sahel. GeoJournal, 48, 299-311. https://doi.org/10.1023/A:1007059403077

Fauchereu, N., Trzaska, S., Rouault, M., \& Richard, Y. (2003). Rainfall Variability and Changes in Southern Africa during 20th Century in the Global Warming Context. Natural Hazards, 29, 139-154. https://doi.org/10.1023/A:1023630924100

Gaughan, A. E., \& Waylen, P. R. (2012). Spatial and Temporal Precipitation Variability in the Okavango-Kwando-Zambezi Catchment, Southern Africa. Journal of Arid Environments, 82, 19-30. https://doi.org/10.1016/j.jaridenv.2012.02.007

Gaughan, A. E., Staub, C. G., Hoell, A., Weaver, A., \& Waylen, P. R. (2016). Inter- and Intra-Annual Precipitation Variability and Associated Relationships to ENSO and the IOD in Southern Africa. International Journal of Climatology, 36, 1643-1656. https://doi.org/10.1002/joc.4448

INAE (2011). Estatistics of Quelimane City District. Maputo: National Institude of Statis- 
tics.

Kendall, M. G. (1975). Rank Correlation Methods (4th ed. London: Charles Griffin.

Kottek, M., Grieser, J., Beck, C., Rudolf, B., \& Rubel, F. (2006). World Map of the Köppen-Geiger Climate Classification Updated. Meteorologische Zeitschrift, 15, 259-263. https://doi.org/10.1127/0941-2948/2006/0130

Mann, H. B. (1945). Nonparametric Tests against Trend. Econometria, 13, 245-259. https://doi.org/10.2307/1907187

Marengo, J. A. (2008). Water and Climate Change. Advanced Studies, 22, 83-96. https://doi.org/10.1590/S0103-40142008000200006

Mason, S. J. (2001). El Niño, Climate Change, and Southern African Climate. Environmetrics, 12, 327-345. https://doi.org/10.1002/env.476

Mason, S., \& Jury, M. (1997). Climatic Variability ond Change over the Southern Africa: A Reflection on Underlying Processes. Progress in Physical Geography, 21, 23-50. https://doi.org/10.1177/030913339702100103

Meehl, G. A., Hu, A., \& Santer, B. D. (2009). The Mid-1970s Climate Shift in the Pacific and Relative Roles of Forced Versos Inherent Decadal Variability. Journal of Climate, 22, 780-792. https://doi.org/10.1175/2008JCLI2552.1

Monerie, P. A., Robson, J., Dong, B., Dieppois, B., Pohl, B., \& Dunstone, N. (2019). Predicting the Seasonal Evolution of Southern African Summer Precipitation in the DePreSys3 Prediction System. Climate Dynamics, 52, 6491-6510. https://doi.org/10.1007/s00382-018-4526-3

Nicholson, S. E., \& Kim, J. (1997). The Relationship of the El Niño-Southern Oscillation to African Rainfall. International Journal of Climatology, 17, 117-135. https://doi.org/10.1002/(SICI)1097-0088(199702)17:2<117::AID-JOC84>3.0.CO;2-O

Nicholson, S. E., Funk, C., \& Finkd, A. H. (2018). Rainfall over the African Continent from the 19th through the 21st Century. Global and Planetary Change, 165, 114-127. https://doi.org/10.1016/j.gloplacha.2017.12.014

Ratnam, J. V., Behera, S. K., Masumoto, Y., \& Yamagata, T. (2014). Remote Effects of El Niño and Modoki Events on the Austral Summer Precipitation of Southern Africa. Journal of Climate, 27, 3802-3815. https://doi.org/10.1175/JCLI-D-13-00431.1

Reason, C. J., \& Jagadheesha, D. (2005). A Model Investigation of Recent ENSO Impacts over Southern Africa. Meteorology and Atmospheric Physics, 89, 181-205. https://doi.org/10.1007/s00703-005-0128-9

Richard, Y., Trzaska, S., Roucou, P., \& Rouault, M. (2000). Modification on the Southern African Rainfall Variability/ENSO Realtioship since the Late 1960s. Climate Dynamics, 16, 883-895. https://doi.org/10.1007/s003820000086

Rouault, M., \& Richard, Y. (2005). Intensity and Spatial Extent of Droughts in Southern Africa. Geophysical Research Letters, 32, L15702. https://doi.org/10.1029/2005GL022436

Sen, P. K. (1968). Estimates of the Regression Coefficient Based on Kendall's Tau. Journal of the American Statistical Association, 63, 1379-1389. https://doi.org/10.1080/01621459.1968.10480934

Wang, B., Luo, X., Yang, Y.-M., Sun, W., Can, M. A., Caig, W., \& Liu, J. (2019). Historical Change of El Niño Properties Sheds Light on Future Changes of Extreme El Niño. PNAS, 116, 22512-22517. https://doi.org/10.1073/pnas.1911130116 